\title{
Mycoflora Associated With Pyrethrum Seed and the Integration of Seed Steam Treatment Into Foliar Disease Management Strategies
}

\author{
Jason B. Scott, ${ }^{\dagger}$ Tasmanian Institute of Agriculture, School of Land and Food, University of Tasmania, Burnie, Tasmania 7320, Australia; \\ David H. Gent, United States Department of Agriculture - Agricultural Research Services (USDA-ARS), Forage Seed and Cereal Research \\ Unit, and Oregon State University, Department of Botany and Plant Pathology, Corvallis, OR 97331; Tamieka L. Pearce, Tasmanian Institute \\ of Agriculture, School of Land and Food, University of Tasmania, Burnie, Tasmania 7320, Australia; Sarah J. Pethybridge, School of Inte- \\ grative Plant Science, Section of Plant Pathology and Plant-Microbe Biology, Cornell University, Geneva, NY 14456; Stacey J. Pilkington, \\ Tasmanian Institute of Agriculture, School of Land and Food, University of Tasmania, Burnie, Tasmania 7320, Australia; and Frank S. Hay, \\ School of Integrative Plant Science, Section of Plant Pathology and Plant-Microbe Biology, Cornell University, Geneva, NY 14456
}

\begin{abstract}
A complex of foliar diseases can affect pyrethrum in Australia, but those of greatest importance are ray blight, caused by Stagonosporopsis tanaceti, and tan spot, caused primarily by Didymella tanaceti. Isolation of fungi from pyrethrum seed lots produced over 15 years resulted in recovery of six known pathogens: S. tanaceti, D. tanaceti, Alternaria tenuissima, Colletotrichum tanaceti, Stemphylium botryosum, and Botrytis cinerea. The incidence of $S$. tanaceti and D. tanaceti isolated from seed varied between 0.9 and $19.5 \%$ (mean $=7.7 \%$ ) and 0 and $24.1 \%$ (mean $=5.3 \%$ ) among years, respectively. Commercial heat treatment of pyrethrum seed via steaming reduced the incidence of $D$. tanaceti from 10.9 to $0.06 \%$ and the incidence of $S$. tanaceti from $24.6 \%$ to nondetectable levels $(<0.18 \%)$. In a second experiment, both species were reduced to nondetectable levels $(<0.20 \%)$ from their initial incidences of 22.4 and $2.4 \%$, respectively. In a field study in 2013, colonization of pyrethrum foliage by $S$. tanaceti was reduced from 21.1 to $14.3 \%$ in early winter when heat-treated seed was planted. However, isolation frequency of $D$. tanaceti was not affected

significantly by seed treatment in this year. In a related experiment in 2015 , the isolation frequency of $D$. tanaceti in plots planted from heattreated seed depended on both prior application of an industry-standard fungicide program and proximity to another pyrethrum field in autumn. The fungus was recovered at a similar frequency in fungicide-treated and nontreated plots located near other pyrethrum fields (13.8 versus $16.3 \%$, respectively), whereas recovery of the pathogen was reduced by fungicide applications in geographically remote pyrethrum fields ( 6.7 versus $1.4 \%$, respectively). However, these differences in isolation frequency of $D$. tanaceti in autumn did not obviate the need for later fungicide applications to suppress foliar disease intensity in spring or flower yield in summer, independent of the proximity to other pyrethrum fields. This study suggests that steam treatment of seed can delay development of the foliar disease complex on pyrethrum, although an extremely low level of remaining infected seed or exogenous sources of inoculum necessitates the use of foliar fungicide applications in spring.
\end{abstract}

Pyrethrum (Tanacetum cinerariifolium) is a perennial plant grown commercially for the insecticidal pyrethrins that are produced within secretory ducts on achenes (Zito et al. 1983). Australia produces over half of the world supply of pyrethrins, with crops grown in Tasmania and Victoria (Pethybridge et al. 2008a). Pyrethrum fields are established in spring by direct seeding, with the first harvest approximately 15 months later during the ensuing summer. Over the autumn/winter period and following harvest, plants maintain a vegetative, rosette growth stage. In early spring, plants develop multiple stems that elongate and produce flowers on the terminus of lateral branches (Pethybridge et al. 2008a). Following the first harvest, crops may continue to produce flowers annually over multiple seasons (Pethybridge et al. 2008a).

Foliar dieback of pyrethrum is caused by a complex of diseases that can develop over the vegetative growth period. Of these, ray blight caused by Stagonosporopsis tanaceti (Pethybridge and Wilson 1998; Vaghefi et al. 2012) and tan spot caused by Didymella tanaceti and D. rosea (syn. Microsphaeropsis tanaceti) (Pearce et al. 2016a; Pethybridge et al. 2008c) are predominant. Herein, the tan spot pathogen is referred to generally as $D$. tanaceti to reflect the greater prevalence and incidence of this pathogen relative to $D$. rosea in

${ }^{\dagger}$ Corresponding author. E-mail: Jason.Scott@utas.edu.au

Mention of a trademark, proprietary product, or vendor does not constitute a guarantee or warranty of the product by the USDA and does not imply its approval to the exclusion of the products or vendors that may also be suitable.

Accepted for publication 2 July 2017.

C 2017 The American Phytopathological Society pyrethrum crops in Australia. Other foliar diseases that affect pyrethrum in Australia include: anthracnose caused by Colletotrichum tanaceti (Barimani et al. 2013); pink spot caused by Stemphylium botryosum (Pethybridge et al. 2004); Boeremia blight caused by Boeremia exigua (Jones et al. 2011); and winter blight caused by Alternaria tenuissima (Pethybridge et al. 2004). Additionally, Stemphylium herbarum and Alternaria infectoria have recently been described as foliar pathogens of pyrethrum (Moslemi et al. 2017).

Historically, ray blight has been the most important disease of pyrethrum in Australia (Pethybridge et al. 2005, 2008a, 2013; Pethybridge and Wilson 1998; Vaghefi et al. 2012), and became the primary target of a standardized fungicide program applied to nearly all crops in Australia (Pethybridge et al. 2008a, b, 2011, 2013). Fungicides used for ray blight management typically have been applied only in spring to coincide with stem elongation (Pethybridge et al. 2008 b, 2013). Prior to 2009, defoliation during the rosette stage in autumn and winter from ray blight and other diseases was infrequent, and considered inconsequential (Hay et al. 2015). However, since 2009, extensive defoliation over autumn and winter has become increasingly common in Australian pyrethrum fields. This occurrence has been coincident with a succession of years with above-average rainfall, the emergence of isolates of $D$. tanaceti insensitive to boscalid (Hay et al. 2015), and failures of the spring fungicide control program (Pethybridge et al. 2008b, 2005). Affected plants generally regrow in spring, but emergence of stems is delayed substantially and yield negatively impacted (Pethybridge et al. 2013). Didymella tanaceti has emerged as the dominant species associated with foliar disease during winter and early spring, supplanting $S$. tanaceti and shifting the occurrence of $S$. tanaceti to later spring and summer months (Hay et al. 2015).

Given the potential for extensive defoliation during autumn and winter associated with tan spot, fungicides are now applied routinely 
in both autumn and spring (Hay et al. 2015). The autumn/winter fungicide program has historically involved applications of procymidone (Scott et al. 2014), while fluazinam is also registered for use in Australian pyrethrum crops. Disease control in spring, timed to optimize the protection of developing flower stems (Pethybridge et al. 2013), incorporates a range of chemistries, including the active ingredients boscalid, cyprodinil, azoxystrobin, and chlorothalonil (Pethybridge et al. 2008b, 2005). However, the increasing prevalence and incidence of $D$. tanaceti isolates with reduced sensitivity to boscalid has necessitated a means to reduce reliance on chemical methods for disease management. Both $S$. tanaceti and D. tanaceti can be seedborne in pyrethrum (Pethybridge et al. 2006). Furthermore, ray blight severity is correlated with the incidence of seeds infested with S. tanaceti (Pethybridge et al. 2006), and regional outbreaks of ray blight are closely associated with the planting of infested seed (Pethybridge et al. 2011). In contrast, the importance of seedborne inoculum in the development of tan spot in Australian pyrethrum crops is not well understood. Minimizing seed contamination by these (and other) pathogens may be an important aspect of delaying the onset of foliar disease epidemics, enhancing disease suppression, and/or enabling a reduction in fungicide use. Fungicide treatment of seed prior to planting has been employed by the Australian pyrethrum industry (Pethybridge et al. 2006). However, evidence suggests that seed treatment alone is not completely efficacious for managing ray blight (Pethybridge et al. 2011).

Physical seed treatments such as thermotherapy have been used to eradicate pathogens from seed for over a century (Grondeau and Samson 1994). The Australian pyrethrum industry has proactively adopted heat treatment via seed steaming to improve seed health. However, a thorough validation of the impact of seed heat treatment on foliar disease development is needed, especially given the emergence of $D$. tanaceti as a major pathogen of pyrethrum in Australia. The objectives of this work were to: (i) quantify the incidence of fungi associated with pyrethrum seed in Australia; (ii) validate the efficacy of a commercial-scale heat treatment process for pyrethrum seed used by the Australian pyrethrum industry; and (iii) determine the impact of heat seed treatment on foliar disease development, including any interactions with the Australian pyrethrum industry's fungicide programs.

\section{Materials and Methods}

Mycoflora associated with pyrethrum seed. Samples of nonfungicide-treated pyrethrum seed harvested each year between 2007 and 2015 were obtained from commercial seed crops. Seeds were obtained after harvest and stored at $4{ }^{\circ} \mathrm{C}$ for up to a month before testing. The number of seed lots sampled within a given year ranged from 7 to 15 , with an average of 10.7 lots/year. The number of seed lots evaluated in a given year was $\geq 32 \%$ of all seed lots utilized for sowing all commercial pyrethrum fields in Australia that year. Commercial seed lots are commonly used for sowing multiple years. In such instances, seed lots were only evaluated in the year of seed harvest.

Methods for isolation of fungi from pyrethrum seed were similar to those described by Pethybridge et al. (2006). In brief, 100 to 200 randomly selected seeds from each seed lot were placed on $2 \%$ water agar (WA; Amyl Laboratories, Melbourne, Australia) in Petri dishes. Plates were then incubated in the dark at 20 to $22^{\circ} \mathrm{C}$. Fungi were identified based on morphological characteristics after 5 days and, where necessary, confirmed after 21 days of incubation. Identification was conducted using standard mycological keys (Barnett 1965), and confirmed by comparison with type cultures when necessary. In addition, data for S. tanaceti and D. tanaceti from 2000 to 2006 was obtained from the study of Pethybridge et al. (2006) to enable an extended temporal comparison of the isolation frequency of those species from pyrethrum seed lots. Isolation frequency was recorded as both prevalence (the proportion of seed lots infested with a fungal species) and incidence (the proportion of individual seed within a seed lot infested).

Temporal trends in isolation frequency of S. tanaceti and D. tanaceti were quantified using a nonparametric, locally weighted Loess regression (Cleveland et al. 1988). Loess regression is a modification of a running average smoothing that makes no assumptions about the parametric form of a regression. The method uses a weighted least squares to fit functions of the X-variable at the center of a number of points (the neighborhoods), with the radius of the neighborhood selected based on a smoothing parameter. The Loess regression was fit in the $\mathrm{R}$ statistical language Version 3.1 (R Core Team 2015), with the smoothing parameter selected based on minimizing a modified Akaike Information Criterion (Hurvich et al. 1998).

Efficacy of commercial heat treatment of seed for eradication of seedborne $\boldsymbol{D}$. tanaceti and $\boldsymbol{S}$. tanaceti. Four seed lots obtained in 2012 were treated by Botanical Resources Australia Pty. Ltd. (Ulverstone, Australia) using a proprietary, industry standard, steam treatment procedure. Subsamples of each seed lot were obtained prior to and after treatment to determine the effectiveness of the treatment at eliminating $D$. tanaceti and $S$. tanaceti. The incidence of these pathogens in each subsample was quantified by plating 105 seeds using the methods described above. Thus, isolations were made from a total of 1,680 seeds that were heat-treated or nontreated.

To quantify the efficacy of heat treatment on a larger quantity of seed, two subsamples of 105 seeds from a $14 \mathrm{~kg}$ seed lot were assessed for the incidence of fungi before heat treatment. Following heat treatment, seven subsamples of 210 seeds were placed on WA in Petri dishes and examined for fungi as described above. Data from the first experiment were analyzed using a nonparametric analysis based on rank transformation of the data using an ANOVA-type statistic in the MIXED procedure in SAS Version 9.4 (SAS Institute Inc., Cary, NC). The analysis followed the approach described by Shah and Madden (2004) for a one-factor experimental design. Data from the second experiment were not analyzed as neither pathogen was recovered from the steam-treated seed, as described below. For both experiments, the upper limit of infested seed potentially present was calculated using a one-sided Clopper-Pearson 95\% confidence interval with the formula:

$$
\rho_{U}=1-0.05^{\frac{1}{N}}
$$

where 0.05 is the probability level and $N$ is the total sample size (Madden et al. 2007).

Field trials with heat-treated seed. Experiments were conducted in pyrethrum fields during 2013, 2014, and 2015 to evaluate the effect of heat treatment of seed, in association with the in-season fungicide program on pyrethrum green leaf area, foliar defoliation severity, and flower yield.

2013 study 1. In 2013, a replicated trial was conducted near Moorleah, Tasmania, Australia. In this trial, the individual and combined effects of seed treatment, the standard winter fungicide program for foliar diseases applied over winter and/or spring, and all possible combinations thereof were evaluated in a split-split-plot design. The impact of foliar disease was assessed via estimation of canopy green leaf area.

In the experimental design of this study, the whole-plot factor was seed treatment (heat-treated or nontreated), the subplot factor was spring fungicide program (treated or nontreated), and the subsubplot factor was winter fungicide program (treated or nontreated). Thus, there were eight treatment combinations (i.e., a combination of seed treatment $\times$ winter fungicide program $\times$ spring fungicide program). A split-split plot assigned to a given treatment combination was $3 \mathrm{~m} \times 6 \mathrm{~m}$, and each replicate block contained 3 plots (subsamples) of each treatment. The subplot factor (spring fungicide program) and sub-subplot factor (winter fungicide program) were replicated four times, and the whole plot factor of seed treatment was replicated twice.

The winter fungicide program consisted of three applications of $500 \mathrm{~g}$ a.i./ha fluazinam (Emblem, Crop Care Australia, Brisbane, Australia) applied monthly beginning in late May. The standard spring fungicide program consisted of a single application of $375 \mathrm{~g}$ a.i./ha cyprodinil $+250 \mathrm{~g}$ a.i./ha fludioxonil (Switch, Syngenta Crop Protection, Sydney, Australia), applied when stems were approximately $5 \mathrm{~cm}$ tall (mid-August), followed by $150 \mathrm{~g}$ a.i./ha azoxystrobin 
(Amistar 250 SC; Syngenta Crop Protection) + chlorothalonil (Bravo, Syngenta Crop Protection) at 1,008 liters a.i./ha applied two and four weeks later. Applications were made with a motorized back-pack sprayer fitted with a 1.6-m boom delivering 300 liters/ha using nozzles equivalent to those used in commercial applications of each fungicide.

Canopy reflectance, a correlate of green leaf area, was assessed using a GreenSeeker radiometer (NTech Industries, Ukiah, CA) which captured canopy reflectance every $100 \mathrm{~ms}$ over the entire plot area, and was averaged for individual plots. This information was used to calculate the normalized difference vegetation index (NDVI) from 14 June, 29 July, and 19 September. These dates corresponded with approximately 1 week after the completion of the winter program, 1 week prior to the initiation of the spring program and 1 week after the completion of the spring program, respectively.

Data were analyzed in a generalized linear mixed model using the GLIMMIX procedure in SAS. The NDVI values obtained from the July measurements were analyzed only for the impact of seed treatment (heat-treated or nontreated) and winter fungicide program (treated or nontreated with fungicides in winter) because the spring fungicide programs had not yet been applied. Therefore, the experimental design used for analysis of the NDVI values was a split-plot with subsamples (i.e., multiple plots that had not yet received the spring fungicide applications). Seed treatment and winter fungicide program were fixed factors; block, block $\times$ seed treatment, and winter fungicide program nested within block and seed treatment were random factors. NDVI values obtained in September included the spring fungicide treatments and consequently were analyzed as a split-split plot design. Fixed factors again included seed treatment (heat-treated or nontreated), winter fungicide program (treated or nontreated), and spring fungicide program (treated or nontreated). Block, block $\times$ seed treatment, and spring fungicide program nested within block and seed treatment were random factors. In both analyses, denominator degrees of freedom were determined using a general KenwardRoger approximation (Kenward and Roger 1997). A normal distribution and the associated default link function were utilized in all analyses based on residual diagnostics. When covariance parameter estimates were found to be 0 for a random effect, the random factor

Table 1. Fungi associated with nontreated commercial seed lots of pyrethrum during 2007 to 2015 in Australia ${ }^{\mathrm{a}}$

\begin{tabular}{|c|c|c|c|c|c|c|}
\hline \multirow[b]{2}{*}{ Species } & \multicolumn{3}{|c|}{ Prevalence $^{\mathbf{b}}$} & \multicolumn{3}{|c|}{ Incidence $^{c}$} \\
\hline & Mean & Standard deviation & Range & Mean & Standard deviation & Range \\
\hline Alternaria spp. $^{\mathrm{d}}$ & 100.0 & 0.0 & $100.0-100.0$ & 45.2 & 19.6 & $17.6-71.1$ \\
\hline Aureobasidium pullulans & 90.8 & 24.3 & $35.7-100.0$ & 40.2 & 31.1 & $0.5-69.6$ \\
\hline Botrytis cinerea $^{\mathrm{e}}$ & 37.4 & 36.1 & $0.0-80.0$ & 1.2 & 1.3 & $0.0-3.2$ \\
\hline Cladosporium spp. & 100.0 & 0.0 & $100.0-100.0$ & 39.1 & 18.9 & $10.6-65.6$ \\
\hline Colletotrichum tanaceti ${ }^{\mathrm{e}}$ & 1.9 & 5.0 & $0.0-13.3$ & $<0.1$ & $<0.1$ & $0.0-0.1$ \\
\hline Didymella tanaceti $\mathrm{i}^{\mathrm{e}}$ & 89.0 & 7.9 & $80.0-100.0$ & 6.9 & 7.8 & $0.9-24.1$ \\
\hline Fusarium spp. & 31.3 & 37.9 & $0.0-92.9$ & 1.4 & 3.2 & $0.0-8.7$ \\
\hline Itersonilia perplexans & 5.2 & 9.0 & $0.0-20.0$ & $<0.1$ & 0.2 & $0.0-0.3$ \\
\hline Penicillium spp. & 39.6 & 29.3 & $13.3-85.7$ & 0.9 & 1.5 & $0.1-4.3$ \\
\hline Pithomyces spp. & 25.4 & 31.1 & $0.0-71.4$ & 0.2 & 0.4 & $0.0-1.0$ \\
\hline Stagonosporopsis tanaceti ${ }^{\mathrm{e}}$ & 84.9 & 15.3 & $57.1-100.0$ & 8.2 & 7.2 & $0.9-19.0$ \\
\hline Stemphylium spp. ${ }^{\mathrm{f}}$ & 78.9 & 25.6 & $40.0-100.0$ & 7.4 & 8.1 & $0.6-23.8$ \\
\hline Ulocladium sp. & 71.8 & 31.7 & $13.3-100.0$ & 3.4 & 2.9 & $0.1-8.0$ \\
\hline
\end{tabular}

a Seventy five commercial seed lots were assayed over 2007, 2008, and 2011 to 2015 . An average of 139 seeds (range 98 to 388 ) were assayed per seed lot.

$\mathrm{b}$ Percentage of seed lots on which a particular fungal genus or species was detected within each season.

c Percentage of individual seeds on which a particular fungal genus or species was detected within each season.

${ }^{\mathrm{d}}$ Individual Alternaria species were not differentiated in all survey years; these have been combined at the genus level here. A. tenuissima and A. infectoria are known foliar pathogens of pyrethrum (Moslemi et al. 2017; Pethybridge et al. 2004).

e Known pathogen(s) of pyrethrum (Barimani et al. 2013; Macdonald 1995; Pethybridge et al. 2004, 2008c; Pethybridge and Wilson 1998).

${ }^{\mathrm{f}}$ Individual Stemphylium species were not differentiated in all survey years; these have been combined at the genus level here. S. botryosum and S. herbarum are recorded foliar pathogens of pyrethrum (Moslemi et al. 2017; Pethybridge et al. 2004).
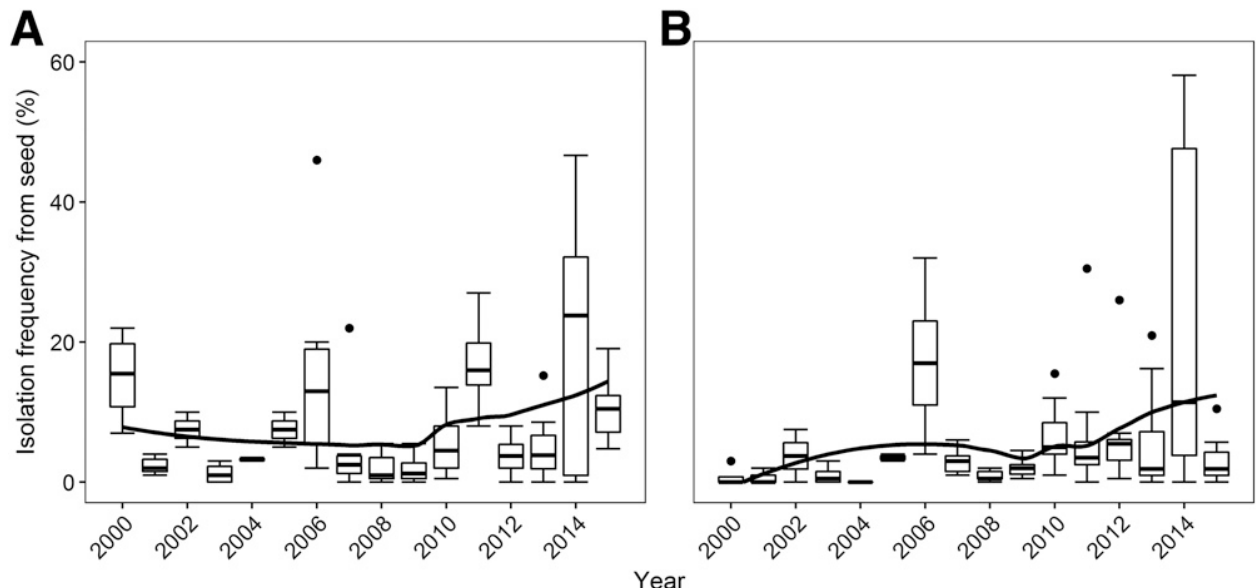

Fig. 1. Temporal changes in the isolation frequency of A, Stagonosporopsis tanaceti, and B, Didymella tanaceti, in nontreated commercial pyrethrum seed in Australia. An average of 8.5 commercial seed lots (range of 2 to 15) were tested each year, with 100 to 200 seeds assayed per seed lot. Data for 2000 to 2006 were obtained from nontreated seed (Pethybridge et al. 2006). The boundary of the box indicates the 25th and 75th percentiles, the line within the box indicates the median, error bars indicate the 10th and 90th percentiles, and black circles indicate outliers. Solid lines indicate temporal trends in isolation frequency fit using nonparametric, locally weighted Loess regressions (Cleveland et al. 1988). 
was removed from the model and the model was refitted. Least square means were compared using the lines options in the GLIMMIX procedure.

2013 study 2. A second study was conducted in 2013 incorporating six commercial pyrethrum fields across northern Tasmania. This study evaluated the impact of seed treatment and spring fungicide applications. The impact of these treatments was assessed using estimates of green leaf area during winter and spring, and defoliation severity in spring.

In each field, the seed lot used to establish the crop in which the experiment was conducted was not heat-treated, and a section of the field 18 to $24 \mathrm{~m}$ wide (field dependent) $\times 20 \mathrm{~m}$ long was sown with heat-treated seed within the field. A strip of equal size in the commercial crop, parallel to the strip sown with heat-treated seed, was marked for comparison. Overlaid on each of these seed treatment strips were plots that received the industry standard spring fungicide program or were not treated with fungicides. The experiment was organized as a split-plot design with the whole plot factor of seed treatment (heat-treated or nontreated) and subplot factor of spring fungicide treatment (treated or nontreated). Thus, there were a total of four treatments. There was one replication of all four treatment combinations per field, and replication (blocking) was over the six fields. Spring fungicide applications were made as described previously. Measurement of NDVI was conducted as described previously, with individual crop observations spread over each of the periods 15 to 26 July and 17 to 27 September. The effect of the treatments on defoliation severity was also measured during the last week of September using established methods (Pethybridge et al. 2008b, 2005). In brief, 20 flowering stems were collected systematically along a diagonal transect across each plot. Stem height and height to defoliation (leaves either completely necrotic or abscised) were measured and used to calculate percent defoliation severity. Data analysis was as explained above, except that seed treatment and spring fungicide program were fixed factors, and block and block $\times$ seed treatment were random factors in the analysis.

2013 fungal isolation frequencies. In 2013, isolations were made from symptomatic pyrethrum leaves collected from commercial pyrethrum fields to determine the identity and frequency of fungal pathogens associated with plants grown from heat-treated versus nontreated seed. At least 20 leaves were collected from individual plants with necrotic lesions and other symptoms characteristic of the winter dieback complex (Hay et al. 2015). Sampling was conducted in the nontreated plots in each of the fields described above for the 2013 strip trials during winter (June/July) and again in early spring (September/October). Leaves were stored at $4^{\circ} \mathrm{C}$ before isolations were conducted. Tissue for each sample was surface-sterilized in $10 \%$ bleach $(0.4 \%$ available $\mathrm{NaClO})$, rinsed three times in sterilized deionized water, and air-dried. Leaf tissue from the edge of a lesion was excised, transferred to a Petri plate containing $2 \% \mathrm{WA}$, and incubated in the dark at 20 to $22^{\circ} \mathrm{C}$. After five days, fungal cultures were identified based on morphological characteristics. Where necessary, emerging mycelium was transferred to potato dextrose agar (PDA; Amyl Laboratories, Melbourne, Australia) and incubated for 5 to 10 days to aid with identification. During the June/July sampling period, isolations were made from 264 and 280 plants within the heattreated and nontreated plots, respectively. In the September/October sampling period, the number of isolations from the heat-treated and nontreated plots were 338 and 330, respectively. The data from all sites were combined, and a $\chi^{2}$ analysis was conducted to test for independence of isolation frequency of a given fungal species from the heattreated and nontreated seed plots. Analyses were conducted in Minitab Version 16 (Minitab Inc., State College, PA).

2014 study. In 2014, trials were conducted across seven commercial pyrethrum fields to evaluate the potential of the heat treatment of seed to reduce the need for in-season fungicide applications for foliar disease control. Treatment effects were assessed via estimation of canopy green leaf area in winter and spring, defoliation severity in spring, and flower yield in summer. Pyrethrum fields utilized for this experiment were planted with commercially heat-treated seed. Due to the entire Australian pyrethrum industry adopting heat treatment for all seed lots prior to the 2013 planting, inclusion of plots established with nontreated seed was not possible at these sites.

Within each field, the experimental design was a factorial including winter fungicide applications (treated or nontreated) and spring fungicide application frequency (nontreated, one application, or three applications). Thus, there was a total of six treatment combinations (two fungicide treatments in the winter $\times$ three spring fungicide application frequencies). The winter fungicide program consisted of two applications of fluazinam, with applications made in late May and mid July. The spring fungicide program plots receiving three fungicide applications consisting of cyprodinil + fludioxonil in mid-August, followed by two biweekly applications of azoxystrobin + chlorothalonil. Plots sprayed once received only the cyprodinil + fludioxonil application. Each plot was 18 to $24 \mathrm{~m}$ wide (field dependent) $\times 20 \mathrm{~m}$ long. Each experiment in a given field was considered a replicate block. Applications were made by pyrethrum growers using available on-farm, tractor driven spray equipment. All fungicides were applied at the rates described for the 2013 trials.

NDVI and defoliation severity were quantified according to the methods used in 2013. On 5 December, flower yield was estimated by automated image analysis as described previously (Scott et al. 2015). Data were analyzed using the GLIMMIX procedure as a factorial design, with fixed factors for winter fungicide treatments, spring fungicide treatments, and the interaction term. Replication was a random factor. Other aspects of the analysis were as described above.

2015 study. In 2015, a study was established across 10 commercial pyrethrum fields planted from heat-treated seed. This study was designed to further quantify whether the Australian pyrethrum industry standard fungicide program was beneficial when crops were sown with heat-treated seed. Impact of experimental treatments was

Table 2. Effects of seed heat treatment and fungicide applications ${ }^{\mathrm{a}}$ made during winter and spring on pyrethrum canopy reflectance as measured by the normalized difference vegetation index (NDVI) in a replicated trial conducted at Moorleah, Tasmania, Australia, in 2013

\begin{tabular}{|c|c|c|c|c|c|c|c|c|c|c|c|c|}
\hline \multirow[b]{2}{*}{ Effect $^{\mathbf{a}}$} & \multicolumn{4}{|c|}{ June } & \multicolumn{4}{|c|}{ July } & \multicolumn{4}{|c|}{ September } \\
\hline & Num $D^{b}$ & Den $D^{b}$ & $F$ & $P$ & Num DF & Den DF & $\boldsymbol{F}$ & $P$ & Num DF & Den DF & $F$ & $P$ \\
\hline Seed & 1 & 3 & 0 & 0.992 & 1 & 3 & 0.28 & 0.631 & 1 & 9 & 3.41 & 0.098 \\
\hline Winter & 1 & 86 & 0.48 & 0.491 & 1 & 86 & 126.7 & $<0.001$ & 1 & 76 & 202.3 & $<0.001$ \\
\hline Seed $\times$ Winter & 1 & 86 & 1.39 & 0.242 & 1 & 86 & 0.10 & 0.757 & 1 & 76 & 0.01 & 0.907 \\
\hline Spring & $-^{\mathrm{c}}$ & - & - & - & - & - & - & - & 1 & 9 & 0.99 & 0.347 \\
\hline Seed $\times$ Spring & - & - & - & - & - & - & - & - & 1 & 9 & 0.35 & 0.570 \\
\hline Winter $\times$ Spring & - & - & - & - & - & - & - & - & 1 & 76 & 0.07 & 0.798 \\
\hline Seed $\times$ Winter $\times$ Spring & - & - & - & - & - & - & - & - & 1 & 76 & 0.16 & 0.692 \\
\hline
\end{tabular}

a Pyrethrum seed was heat-treated according to a proprietary industry standard protocol, or nontreated, and then used to establish plots that were treated or nontreated with fungicides in winter and spring. The experiment was a split-split plot design with a whole plot factor of seed treatment, subplot factor of fungicides applied in spring, and sub-subplot factor of fungicides applied in winter. Data were analyzed by a generalized linear mixed model where treatment was a fixed factor and replication was a random factor.

${ }^{\mathrm{b}}$ Num DF and Den DF = numerator and denominator degrees of freedom, respectively.

c Spring fungicide applications were initiated in August 2013. 
assessed via estimates of canopy green leaf area in winter and spring, defoliation severity in spring, and flower yield in summer. Additionally, the isolation frequency of foliar pathogens was monitored from autumn to late winter.
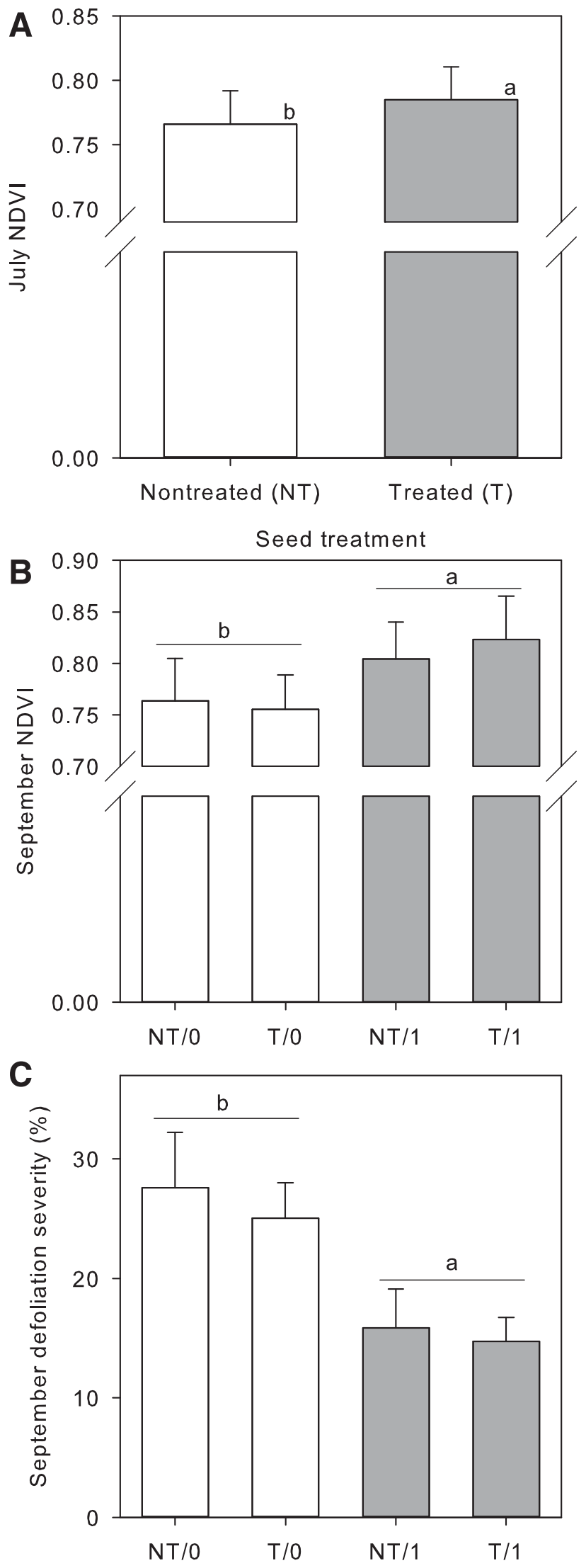

Seed treatment/Spring fungicide applications
In each field, two plots were established with dimensions identical to those used in the 2013 strip trials. One of the plots was not treated with fungicides and the other received both the standard winter and spring fungicide programs described above. Fungicide applications were made by pyrethrum growers using their standard pesticide application equipment. The distance of each trial to the surrounding pyrethrum fields was mapped. A field was considered geographically remote if there was not a pyrethrum field within $2 \mathrm{~km}$ at the time of sowing, and not geographically remote otherwise. Measurements of NDVI, defoliation severity, and flower yield were made as described for trials in previous years. Experimental design and analysis were the same as in 2014 .

Isolations were made from necrotic lesions on leaves collected from each of the 10 fields using the methods described for the 2013 trials. Fifty-two isolations were conducted per plot at each site during early May, July, and August. The isolation frequency of D. tanaceti and $S$. tanaceti were analyzed by sampling month in a generalized linear model, with fixed factors for fungicide treatment (treated or nontreated), isolation of the field (geographically remote or not remote), and the interaction of these factors. Site was treated as a random factor. Attempts to normalize the discrete data by transformation were not successful; therefore, the data were analyzed assuming a Poisson or negative binomial distribution of the response variable in a generalized linear mixed model using the GLIMMIX procedure.

\section{Results}

Mycoflora associated with pyrethrum seed. Thirteen fungal genera were detected in the pyrethrum commercial seed lots harvested between 2007 and 2015 (Table 1). The fungi with the highest prevalence on seed lots were Cladosporium spp., Aureobasidium pullulans, Alternaria spp., S. tanaceti, and D. tanaceti. The incidence of infested seed per seed lot varied across the seed lots tested for most of the fungal species (Table 1), with prevalence ranging from 1.9 to $100 \%$ within years and mean incidence on seeds ranging from below detection limits to $45.2 \%$ among organisms.

There was seasonal variation in the isolation frequency of fungal pathogens from pyrethrum seed across the years 2007 to 2015 (Table 1). For both $S$. tanaceti and $D$. tanaceti, incidence varied more than 10 -fold among certain years. Stagonosporopsis tanaceti was isolated from an average of $0.9 \%$ of seeds per seed lot in 2007 compared with $19.0 \%$ in 2014 . The incidence of seed infested with $D$. tanaceti varied from $0.9 \%$ of seeds per seed lot in 2008 to $24.1 \%$ in 2014. Stemphylium spp., including $S$. botryosum, was isolated from 0.6 to $23.8 \%$, depending on the year (Table 1). Colletotrichum tanaceti was found in two seed lots in 2013, although the incidence was limited to $<1.0 \%$ per seed lot. The flower blight pathogen, Botrytis cinerea, was not recovered from seed in 2007 or 2015 . In years where $B$. cinerea was recovered, mean incidence ranged from $<0.1$ in 2011 , to $3.2 \%$ per seed lot in 2014. Alternaria spp. were recovered from $100 \%$ of seed lots tested, with a mean incidence of infestation ranging from 17.6 to $71.1 \%$ per seed lot among years. Individual Alternaria species were not identified in all survey years. However, in years where species were identified, the pyrethrum pathogen A. tenuissima was present in all seed lots, at incidences ranging from 1.5 to $43.0 \%$ per seed lot $($ mean $=13.0 \%)$.

Fig. 2. Effect of heat treatment of seed and fungicide applications in spring on defoliation severity of pyrethrum by a foliar disease complex. A, Canopy reflectance based on NDVI (Normalized Difference Vegetation Index) in the winter (July) in relation to seed treatment. B and C, Canopy reflectance and defoliation severity in austral spring (September) in relation to seed treatment $(\mathrm{NT}=$ nontreated; $\mathrm{T}=$ heattreated) and fungicide applications in spring $(0=$ nontreated; $1=$ treated). Data were collected in 2013 from plots established in each of six commercial pyrethrum fields in Tasmania, Australia. In B and C, data were analyzed as a split plot design with seed treatment the whole plot factor, spring fungicide the subplot factor, and block (replication) over fields. Means sharing a common letter were not significantly different based on a mixed model analysis $(\alpha=0.05)$. In $\mathbf{B}$ and $\mathbf{C}$, interaction terms were not significant $(P=0.278$ and 0.912 , respectively). Error bars indicate standard errors. 
Incidence of $D$. tanaceti and $S$. tanaceti in seed varied substantially over the period from 2000 to 2015 (Fig. 1). During 2000 to 2009, there was generally a decreasing frequency of isolation of $S$. tanaceti (15.0\% in 2000 versus $1.9 \%$ in 2009). The trend in isolation frequency of D. tanaceti over this period indicated a slight increase from 2000 $(0.8 \%)$ to 2009 (2.2\%). However, isolation incidence of both pathogens was notably higher in 2006 (16.3\% for S. tanaceti and $17.3 \%$ for D. tanaceti). After 2009, the incidence of both pathogens tended to increase, being isolated from at least 3.3\% of seed in all years (Fig. 1).

Efficacy of commercial heat treatment of seed for eradication of seedborne $D$. tanaceti and $S$. tanaceti. Heat treatment of seed significantly $(P<0.0001)$ reduced the incidence of the major seedborne pathogens, $D$. tanaceti and $S$. tanaceti. The incidence of $D$. tanaceti and $S$. tanaceti in nontreated seed was 10.9 and $24.6 \%$, respectively, and $0.06 \%$ and nondetectable, respectively, in heat-treated seed. Based on assaying a total of 1,680 seeds, the upper $95 \%$ limit of the Clopper-Pearson interval was 0.0018. That is, with this sample size there was a $95 \%$ probability that as many as $0.18 \%$ of the seeds were infested even when a specific fungus was not detected.

In the second experiment, $D$. tanaceti and $S$. tanaceti were detected in 22.4 and $2.4 \%$ of the seed prior to treatment, respectively. Following heat treatment, neither organism was detected in the 1,470 seeds tested. The upper $95 \%$ limit of the Clopper-Pearson interval was $0.203 \%$.

Field trials with heat-treated seed. 2013 study 1 . Seed treatment alone or the interaction of seed treatment with other main factors was not significantly associated with changes in NDVI $(P \geq 0.242)$ (Table 2). Fungicide treated plots had higher NDVI values in winter (July) and early spring (September) $(P<0.001$ for both periods). In July, NDVI was 0.64 (95\% least square means confidence interval [CI] of 0.58 to 0.69$)$ in fungicide-treated plots, and $0.55(\mathrm{CI}=0.50$ to 0.61 ) in plots not treated with fungicides. Similarly, in September NDVI was $0.68(\mathrm{CI}=0.65$ to 0.71$)$ in fungicide-treated plots versus $0.61(\mathrm{CI}=0.58$ to 0.64$)$ in plots that did not receive fungicides.

2013 study 2. NDVI was significantly greater in July in plots established from heat-treated seed compared with those established with nontreated seed $(P=0.045$; Fig. $2 \mathrm{~A})$, with NDVI values of 0.79 $(\mathrm{CI}=0.68$ to 0.85$)$ versus $0.77(\mathrm{CI}=0.70$ to 0.87$)$, respectively. However, the effects of seed treatment on NDVI did not persist into spring. Plots treated with the spring foliar fungicide program had significantly higher NDVI than nontreated plots $(P=0.0003$; Fig. $2 \mathrm{~B})$, but there was no evidence that seed treatment affected NDVI $(P=$ 0.664 ) or that seed treatment interacted with the spring fungicide program $(P=0.280)$. Defoliation severity was reduced from 26 to $15 \%$ with the spring fungicide program $(P=0.0002$; Fig. $2 C)$, although there was no evidence that seed treatment influenced disease severity $(P=0.419)$ or affected efficacy of the spring fungicide program $(P=0.764)$.

2013 fungal isolation frequencies. In 2013, the pathogens most frequently isolated from leaves collected from fields sown with treated and nontreated seed were $S$. tanaceti, D. tanaceti, C. tanaceti, and Stemphylium spp. Stagonosporopsis tanaceti was isolated from 38 of 264 pyrethrum plants grown from heat-treated seed and 59 of 280 plants grown from nontreated seed during winter (June/July). The isolation frequency differed significantly $(P=0.033)$ between the seed treatments for $S$. tanaceti but not for $D$. tanaceti, $C$. tanaceti, or Stemphylium spp. (Table 3). The difference in isolation frequency of $S$. tanaceti in spring (September/October) was less pronounced between heat-treated and nontreated seed $(P=0.067)$ compared with the autumn, with 26 of 338 isolations from plants sown from treated seed yielding $S$. tanaceti compared with 41 of 330 isolations from nontreated plants. Isolation frequencies of $D$. tanaceti, $C$. tanaceti, and Stemphylium spp. were statistically similar among plants grown from heat-treated or nontreated seed (Table 3). During spring, D. tanaceti was the primary fungal species recovered from necrotic lesions.

2014 study. In 2014, NDVI differed significantly between winter fungicide treated and nontreated plots $(P=0.014$; Fig. 3A). NDVI averaged $0.61(\mathrm{CI}=0.44$ to 0.74$)$ in fungicide-treated plots versus $0.59(\mathrm{CI}=0.47$ to 0.72$)$ in nontreated plots. As stem elongation commenced in September, the impact of the winter fungicide program diminished and there was no detectable effect of the winter fungicide applications on NDVI $(P=0.162)$. However, there was a significant improvement in NDVI associated with the spring fungicide program $(P=0.006)$, independent of whether or not fungicides were applied in winter $(P=0.110$; Fig. 3B). Plots receiving fungicides in spring, either once or three times, had mean NDVI values of $0.73(\mathrm{CI}=0.64$ to 0.82 ) and $0.74(\mathrm{CI}=0.65$ to 0.83$)$, respectively, both of which were significantly greater than the NDVI in nontreated plots (mean $=0.71$; $\mathrm{CI}=0.63$ to 0.80 ). A similar pattern in defoliation severity was found during October (Fig. 3C). Fungicide applications in spring, irrespective of the number of applications made, significantly reduced disease severity $(P=0.002)$, independent of the winter fungicide application history $(P=0.105$; interaction term $P=1.00)$. By October, defoliation severity averaged $24.9 \%$ in nontreated plots $(\mathrm{CI}=$ 20.9 to $28.9 \%$ ), which was significantly greater than defoliation severity in plots receiving only one fungicide application (mean = $20 \%$; $\mathrm{CI}=16.0$ to $24.1 \%)$ or three fungicide applications $(17.5 \%$; $\mathrm{CI}=13.5$ to $21.5 \%$ ) (Fig. $3 \mathrm{C}$ ).

Flower yield was affected significantly by the frequency of fungicide applications made in spring $(P<0.001)$, but there was no evidence that flower yield improved as a result of fungicide applications made in winter $(P=0.869$; interaction term $P=0.692)$. Plots that did not receive fungicides in spring exhibited a significant $(28 \%)$ reduction in flower yield relative to plots that received three spring fungicide applications (Fig. 3D).

2015 study. Isolations from plants sown with heat-treated seed yielded $D$. tanaceti most frequently across all sampling time periods, field locations (remote or not remote), and foliar fungicide programs (Fig. 4). The frequency of isolation of D. tanaceti from nontreated plots increased over the winter months, and this pathogen was recovered from $34 \%$ of necrotic lesions by August compared with $11 \%$ in May and 30\% in July (Fig. 4). In contrast, recovery of S. tanaceti did not increase over time, and this pathogen was never recovered from more than $15 \%$ of lesions (Fig. 4).

In the first sampling period in May, the isolation frequency of $D$. tanacet $i$ was affected significantly by whether the plants were treated with fungicides and the proximity to other pyrethrum fields (interaction term $P=0.047$; Fig. 4). The fungus was recovered at a similar frequency in fungicide-treated and nontreated plots that were located near other pyrethrum fields (13.8 versus $16.3 \%$, respectively), whereas recovery of the pathogen was reduced by fungicide applications in geographically remote pyrethrum fields (6.7 versus $1.4 \%$, respectively).

Table 3. Isolation frequency of Stagonosporopsis tanaceti, Didymella tanaceti, Stemphylium spp., and Colletotrichum tanaceti from necrotic lesions on pyrethrum foliage when plants were established from heat-treated and nontreated seed ${ }^{\mathrm{a}}$

\begin{tabular}{|c|c|c|c|c|c|c|c|c|c|c|}
\hline \multirow[b]{2}{*}{ Treatment } & \multicolumn{5}{|c|}{ Isolation frequency (June/July) } & \multicolumn{5}{|c|}{ Isolation frequency (September/October) } \\
\hline & $N$ & S. tanaceti & D. tanaceti & C. tanaceti & Stemphylium spp. & $N$ & S. tanaceti & D. tanaceti & C. tanaceti & Stemphylium spp. \\
\hline Heat-treated & 264 & $38(14.4)$ & $20(7.6)$ & $12(4.5)$ & $3(1.1)$ & 338 & $26(7.7)$ & $116(34.3)$ & $29(8.6)$ & $11(3.3)$ \\
\hline Nontreated & 280 & 59 (21.1) & 30 (10.7) & $14(5)$ & $5(1.8)$ & 330 & $41(12.4)$ & $113(34.2)$ & 39 (11.8) & $8(2.4)$ \\
\hline$\chi^{2}$ & & 4.54 & 2.00 & 0.15 & 0.50 & & 3.36 & 0.04 & 1.47 & 0.47 \\
\hline$P$ value & & 0.033 & 0.157 & 0.695 & 0.480 & & 0.067 & 0.843 & 0.225 & 0.491 \\
\hline
\end{tabular}

${ }^{a}$ Isolations were made from pyrethrum plants sown from heat-treated or nontreated seed planted in seven commercial fields across northern Tasmania, Australia, during 2013. For a given organism within a sampling period, the $\chi^{2}$ statistic and associated $P$-values indicate differences in the isolation frequency between heattreated and nontreated seed. Values in parentheses indicate the percentage isolation frequency. 
After May, the proximity to other pyrethrum fields was not a significant factor in the frequency of isolation of D. tanaceti $(P \geq 0.127$ in all analyses), with fungicide treatment only influencing (reducing) significantly the isolation frequency of this pathogen in August $(P=0.011)$.

Stagonosporopsis tanaceti was present at relatively limited incidences on symptomatic pyrethrum tissues across all sampling times (Fig. 4). Foliar fungicide treatments caused a slight reduction in frequency of isolation of $S$. tanaceti in July $(P=0.053,14.9 \%$ of isolations in nontreated plots versus $10.4 \%$ in treated plots). There was no evidence that proximity to existing pyrethrum fields influenced the isolation frequency of this organism, either alone or in interaction with the fungicide treatments $(P \geq 0.226)$ (Fig. 4).
Fungicide applications increased the mean NDVI in August $(P=$ $0.023)$ and September $(P=0.012)$ compared with the NDVI of nontreated plots (Fig. 5A and 5B). Remoteness of the plots from other pyrethrum fields did not affect NDVI significantly $(P=0.697$ in August and 0.492 in September), nor did the distance to other pyrethrum fields influence the effect of the fungicides (interaction term $P=0.715$ in August and 0.914 in September). The effect of foliar fungicide applications persisted into October, reducing defoliation severity from 30 to $28 \%(P=0.002$; Fig. 5C). As with previous NDVI measurements, defoliation severity was independent of distance of the plots to other pyrethrum fields $(P=0.650)$, and the fungicide effect similarly did not interact significantly with plot distance to other fields $(P=0.732)$. Flower yield was increased

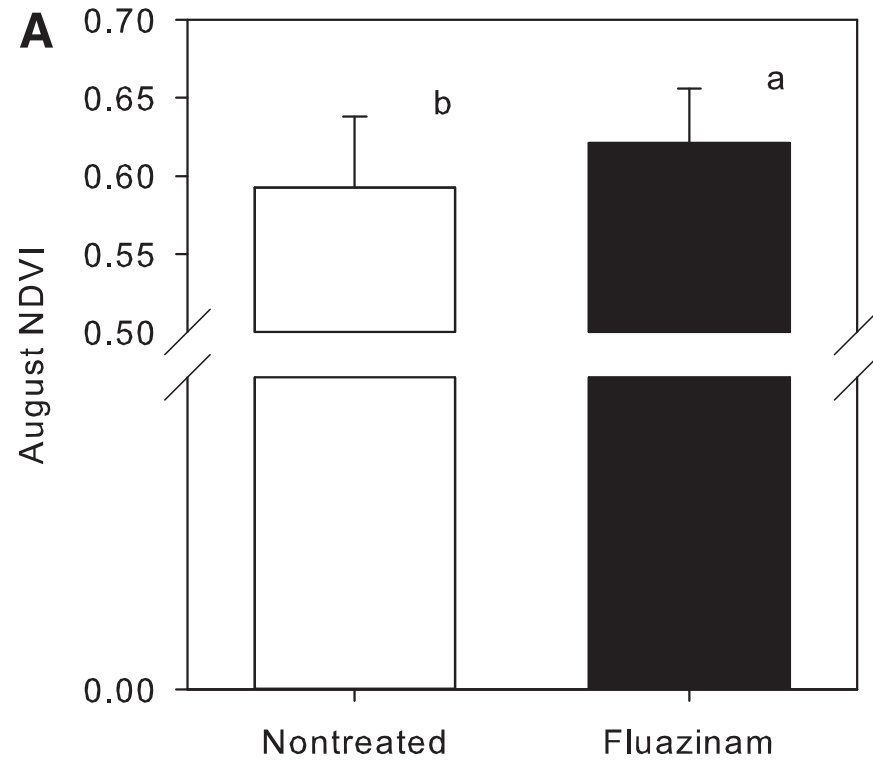

Winter fungicide

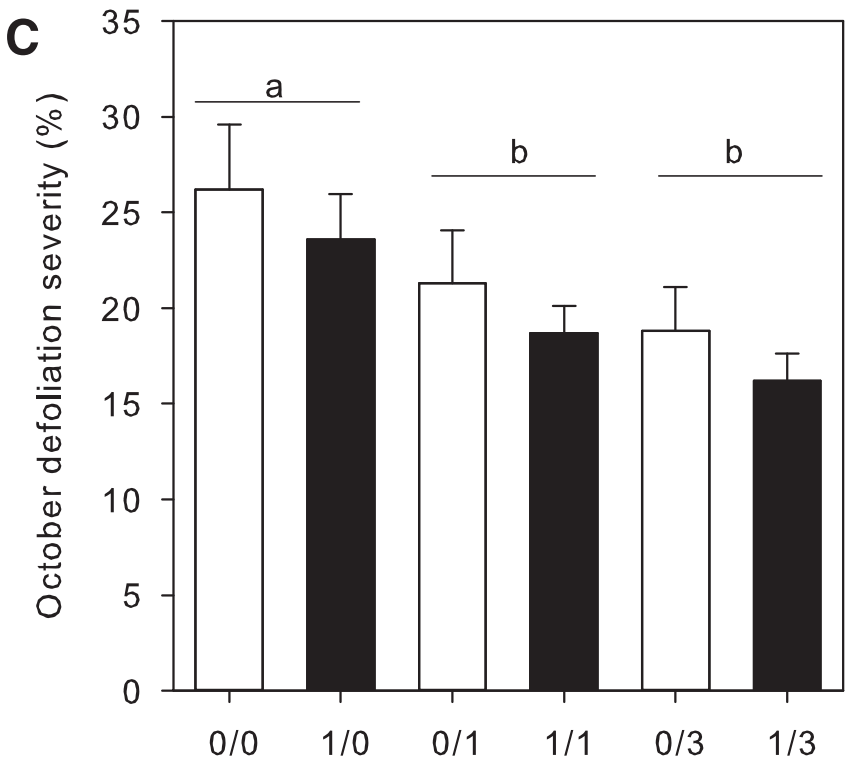

Number of winter/spring applications

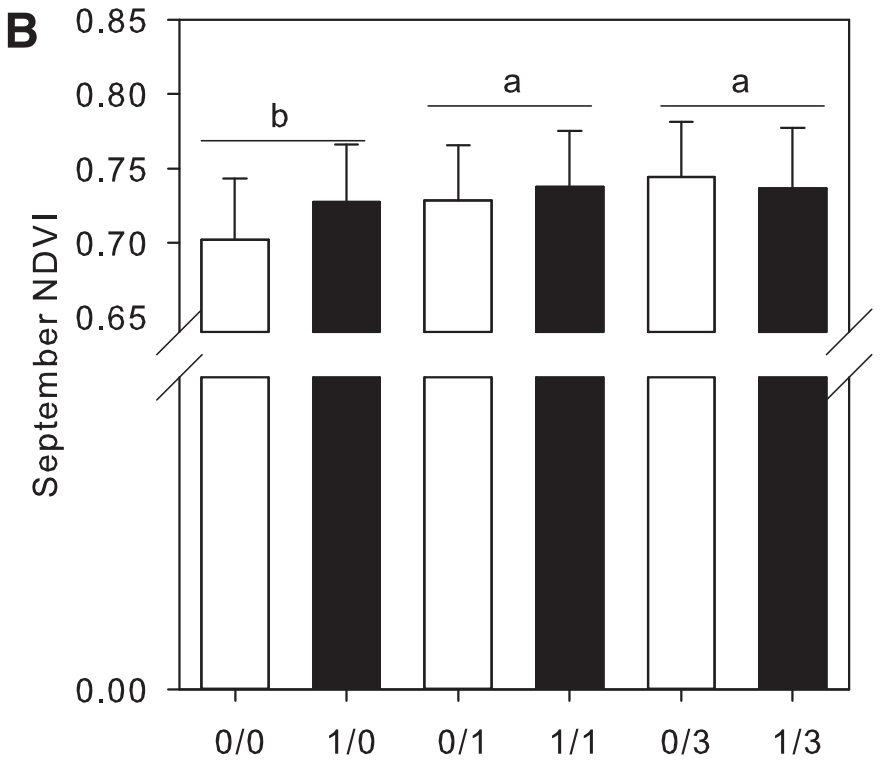

Number of winter/spring applications

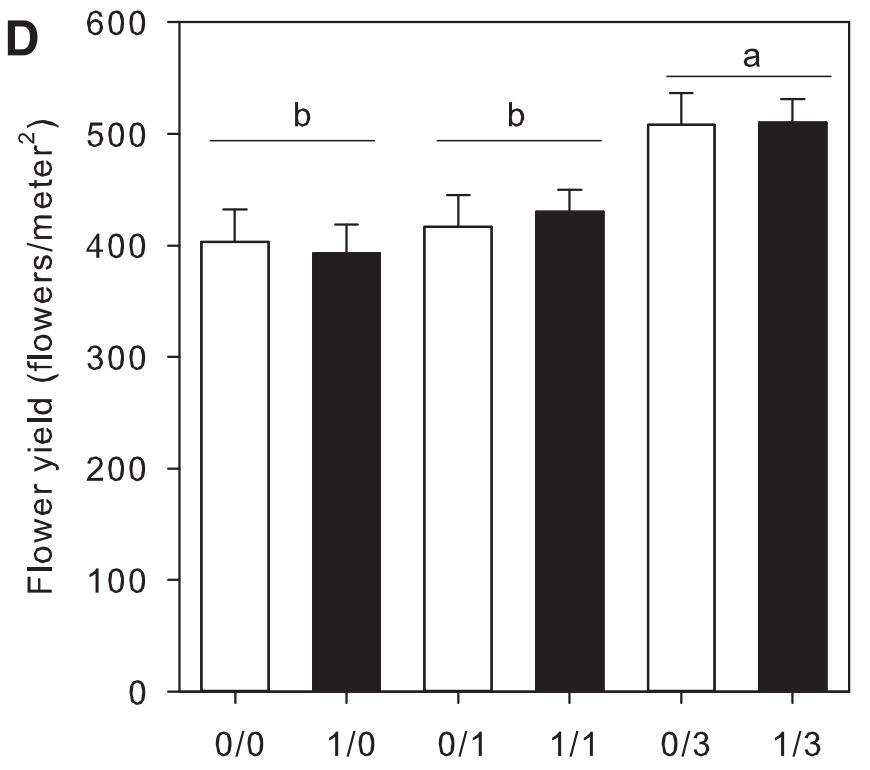

Number of winter/spring applications

Fig. 3. Effect of winter and spring fungicide applications on canopy reflectance (NDVl; Normalized Difference Vegetation Index) (A and B), defoliation severity in October (C), and flower yield (D) in commercial pyrethrum fields planted in Australia with heat-treated seed. White bars each represent the mean for a treatment in which a plot did not receive the winter fungicide applications; black bars represent the means for plots that did receive winter fungicide applications. Data were from plots established in six replicate pyrethrum fields in northern Tasmania, Australia, during 2014. In B to D, data were analyzed as a factorial design with winter fungicide applications [nontreated (0/.) or treated with fluazinam $(1 /)$.$] and spring fungicide application intensity [nontreated (./0), one application (./1), or three applications (./3)] as main factors. Means sharing a common letter were not$ significantly different based on a mixed model analysis $(\alpha=0.05)$. In $B$ to $D$, means for winter fungicide $\times$ spring fungicide treatment combinations are presented, although the main effect of winter fungicide application and the interaction term were not significant ( $P \geq 0.105$ in all instances). Error bars indicate standard errors. 
significantly by foliar fungicide treatments $(P=0.013)$, but not by geographic remoteness of the plots from other pyrethrum fields $(P=0.600)$ or the interaction between plot remoteness and foliar fungicide treatments $(P=0.690$; Fig. 5D).

\section{Discussion}

Commercial seed lots of pyrethrum in Australia are commonly infested with known fungal pathogens, including $S$. tanaceti and $D$. tanaceti, which have been associated with severe foliar disease and significant crop loss in the absence of intensive fungicide programs (Pethybridge et al. 2008b, c, 2005). These pathogens often occurred at relatively high levels in seed lots, confirming previous findings (Pethybridge et al. 2006). Seedborne $S$. tanaceti has been associated with overwintering populations and subsequent severity of ray blight in spring (Pethybridge et al. 2006, 2011). Temporal patterns of increasing prevalence and incidence of $D$. tanaceti in pyrethrum seed lots since 2009 coincide with the emergence of tan spot as an important disease in pyrethrum and the increasing incidence of boscalid-insensitive strains (Hay et al. 2015). Other mycoflora commonly encountered in pyrethrum seed included Aureobasidium pullulans and members of the genera Alternaria, Cladosporium, Stemphylium, and Ulocladium. Previous studies have suggested that A. alternata, Cladosporium spp. and Ulocladium spp. associated with pyrethrum tissues are saprophytic rather than pathogenic in nature (Pethybridge et al. 2004). Similarly, Aureobasidium pullulans is a common endophyte of many temperate plant species (McCormack et al. 1995; Parsa et al. 2016; Webb and Mundt 1978), although it has been associated with postharvest diseases of some fruit crops (Dobra et al. 2015; Kim 2014; Rist and Rosenberger 1995). While species such as A. tenuissima, A. infectoria, S. botryosum, and S. herbarum have been demonstrated to be pathogenic to pyrethrum (Moslemi et al. 2017; Pethybridge et al. 2004), they are currently minor components of the foliar disease complex afflicting pyrethrum (Hay et al. 2015). Thus, $S$. tanaceti and $D$. tanaceti remain the focus for commercial efforts to improve seed health. However, the potential for other organisms to be seedborne may be an important consideration if these pathogens and their diseases become more damaging to pyrethrum.
The Australian pyrethrum industry has proactively developed and commercialized heat treatment of seed as a means of improving seed health. Based on this study, commercial-scale heat treatment of pyrethrum seed lots has reduced the incidence of seedborne fungi, including potential and known pathogens. Based on the seed examined in this study, heat treatment reduced the incidence of $S$. tanaceti to below detectable levels $(\leq 0.20 \%)$ and incidence of $D$. tanaceti to (no more than) one infected seed in 1,680. However, it is not clear what level of seedborne inoculum is sufficient to initiate ray blight and tan spot epidemics and therefore if the efficacy of the current heat treatment is adequate.

In this study, D. tanaceti was the dominant pathogen isolated from necrotic leaf lesions in pyrethrum fields in Australia, confirming findings by Hay et al. (2015). In 2013, seed treatment reduced the isolation frequency of $S$. tanaceti during the first winter (June/July) following sowing of the seed and the ensuing spring (September/ October), indicating that heat treatment of seed can delay colonization of pyrethrum by $S$. tanaceti. In entire fields planted from heattreated seed in 2015, recovery of $S$. tanaceti from necrotic tissue was relatively infrequent during the winter months. In contrast, the impact of seed treatment on D. tanaceti was less pronounced. In 2013, there was no detectable impact of seed treatment on the isolation frequency of $D$. tanaceti during winter or spring. However, the 2015 study indicated that the rapidity of recolonization of pyrethrum by $D$. tanaceti was influenced by proximity to other pyrethrum fields. These observations suggest that seedborne $D$. tanaceti may not be the only source of inoculum for outbreaks of tan spot, and crops planted from seed with a limited or nondetectable incidence of $D$. tanaceti can be recolonized by the pathogen prior to the onset of winter from other inoculum sources. The more rapid recolonization of pyrethrum foliage detected by $D$. tanaceti than $S$. tanaceti following heat treatment of seed in this study may reflect fundamental differences in the biology of these fungi. Fungal pathogens may have different tolerances to heat treatments in other cropping systems, such as in spinach seed (du Toit and Hernandez-Perez 2005) and horseradish rootstocks (Eranthodi et al. 2010). Didymella tanaceti may better survive heat treatment and, therefore, persist at low incidence on seed compared with $S$. tanaceti. Alternatively, D. tanaceti may be more prevalent

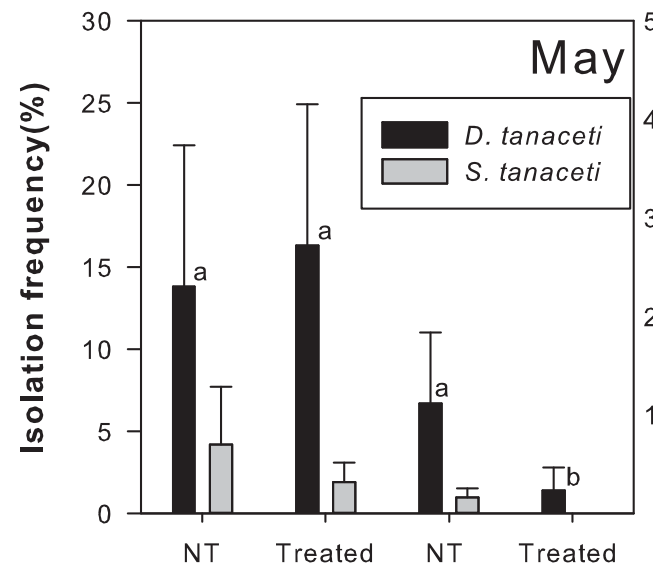

Not remote

Remote

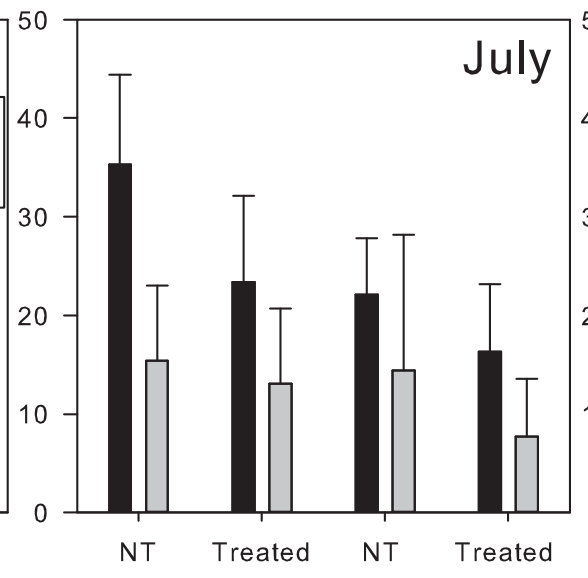

Not remote
Remote

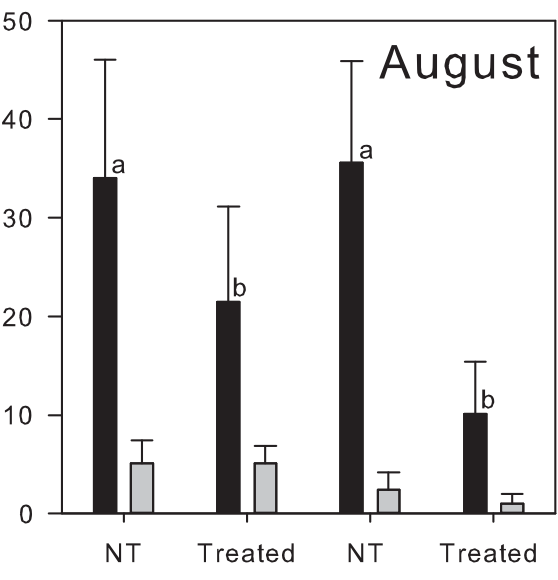

Not remote
Remote

\section{Fungicide treatment Proximity to other pyrethrum fields}

Fig. 4. Isolation frequency of Didymella tanaceti and Stagonospora tanaceti from necrotic lesions on pyrethrum leaves from plants established from heat-treated seed, in relation to foliar fungicide treatment and proximity to other pyrethrum fields. The fungicide treatments were nontreated (NT) and treated with the standard commercial fungicide program (Treated) of five applications during winter and spring. A field was considered geographically remote if there were no other pyrethrum crops within at least $2 \mathrm{~km}$, and not remote otherwise. Data are from 10 pyrethrum fields sampled in 2015, of which six were considered not geographically remote. A total of 52 isolations for fungi were made from necrotic lesions in each fungicide treatment plot in each field during May, July, and August. Data were analyzed as a factorial design with fungicide applications (nontreated or treated) and geographic remoteness from other pyrethrum fields (Remote or Not remote) as main plot factors. Means followed by the same letter were not significantly different based on generalized mixed model analysis at $\alpha=0.05$. Proportions are presented in the figure for ease of interpretation, although data were analyzed based on the number of tissue pieces that yielded a given fungal genus or species (i.e., a Poisson or negative binomial distribution of the response variables). Error bars indicate standard errors. 
or dispersible than $S$. tanaceti, and/or D. tanaceti may be more virulent (have a greater rate of disease increase) than $S$. tanaceti during winter conditions in parts of Australia where this crop is grown. This may be supported by previous studies that indicated $D$. tanaceti is more prevalent than $S$. tanaceti on pyrethrum foliage over winter and spring (Hay et al. 2015).

Both D. tanaceti and S. tanaceti are heterothallic and have the potential to produce an ascigerious stage that forms wind-blown ascospores capable of longer-distance dispersal than the conidial stages (Chilvers et al. 2014; Pearce et al. 2016b). Although the sexual morph of neither organism has been confirmed, both mating-types of $D$. tanaceti have been detected at similar frequencies in Australian pyrethrum fields, and a cryptic sexual stage may occur (Pearce et al. 2016b). In contrast, only one mating-type idiomorph of $S$. tanaceti has been found in Australia (Vaghefi et al. 2015). Therefore, the rapid recolonization of geographically isolated crops by $D$. tanaceti relative to $S$. tanaceti in this study might reflect the greater dispersal potential of the former via ascosporic inoculum. Further confirmation of the presence of the sexual morph and the potential role of alternative hosts is needed.
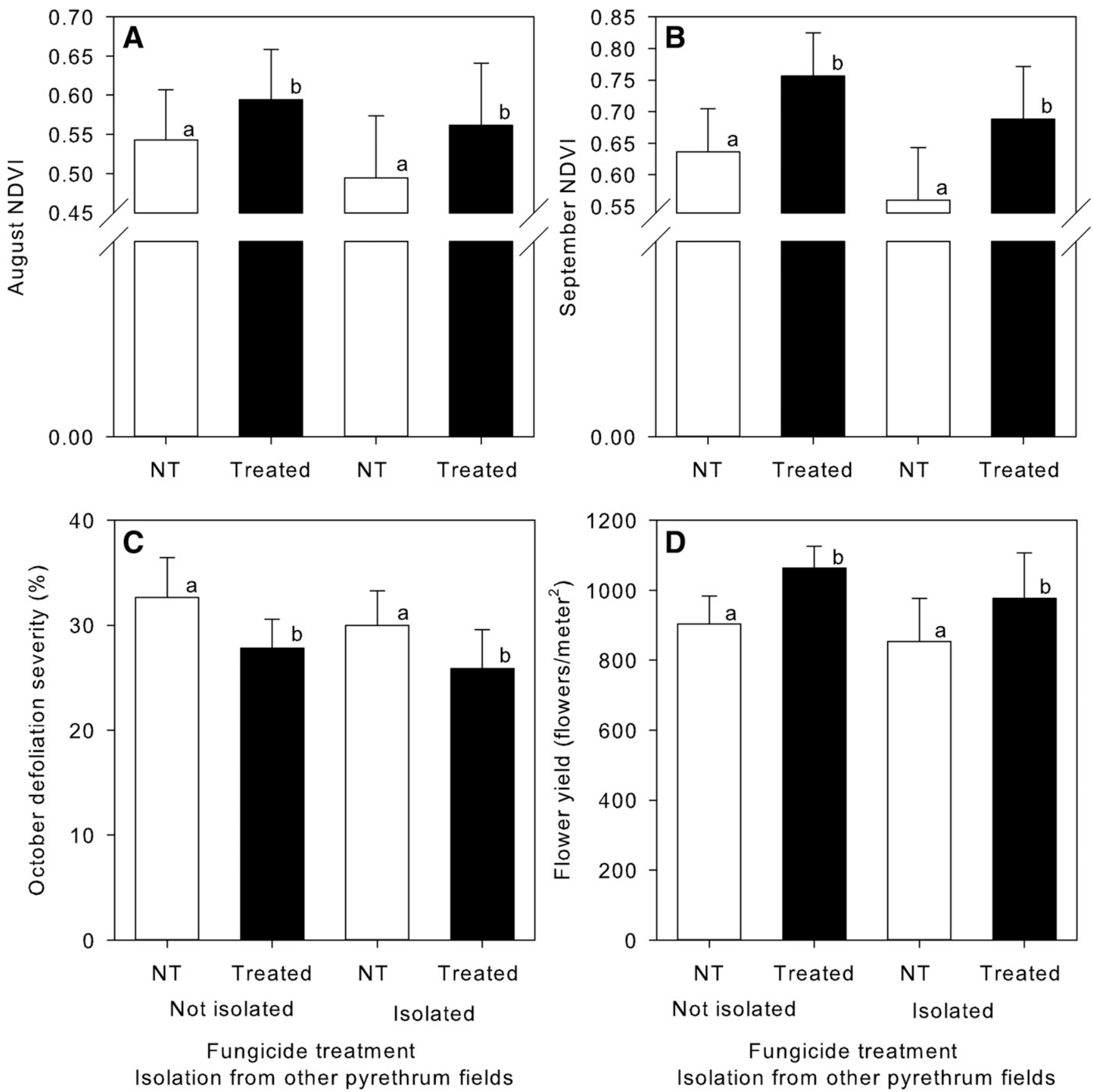

Fig. 5. Effect of winter and spring fungicide applications and proximity to other pyrethrum fields on canopy reflectance (NDVI; Normalized Difference Vegetation Index), A and B, severity of defoliation in October, C, and flower yield, D, in fields planted with heat-treated seed. The fungicide treatments were nontreated (NT) and treated with the standard commercial fungicide program (Treated) during winter and spring. White bars represent the mean for plots not receiving fungicides; black bars indicate the mean for plots treated during both winter and spring with fungicides. A field was considered geographically remote if there were no other pyrethrum crops within at least $2 \mathrm{~km}$, and not geographically remote otherwise. Data are from 10 pyrethrum fields sampled in 2015, of which six were considered not geographically remote. Data are from plots established in 10 replicate pyrethrum fields in northern Tasmania, Australia, during 2015. Data were analyzed as a factorial design with fungicide applications (nontreated or treated) and geographic remoteness from other pyrethrum fields (Remote or Not Remote) as main plot factors. Means sharing a common letter are not significantly different based on a mixed model analysis $(\alpha=0.05)$. Means for fungicide treatment $\times$ geographic remoteness are presented, although only the main factor of fungicide treatment was significant in the analyses. Error bars indicate standard errors. 
Strip trials in commercial fields conducted in 2013 in this study indicated that the overall effect of heat-treatment of seed was a delay in the onset of the foliar disease epidemic during the winter, although this effect was transient. Irrespective of the planting of heat-treated or nontreated seed, the winter and spring fungicide programs had a significant effect on NDVI in winter, and reduced defoliation severity in spring. Thus, even when heat-treated seed is used for field establishment, it is advisable to apply the industry standard fungicide program. Similar to the findings of Hay et al. (2015), the impact of the winter fungicide program was ephemeral and did not affect yield or the temporal dynamics of the disease complex in spring. These results suggested that in-season disease control and maximum flower yield still required application of the entire standard fungicide program in spring.

A basic epidemiological principle is that reduction of primary inoculum may delay disease onset caused by polycyclic pathogens, with the magnitude of disease suppression proportional to epidemic duration (Madden et al. 2007). In the perennial Australian pyrethrum production system, there is a period of approximately seven months from planting seed to the first overwintering period, and 15 months from planting to first harvest. This appears to be a sufficiently long period for reinfection by $D$. tanaceti and, to a lesser extent, $S$. tana$c e t i$, even when heat-treated seed is planted. For example, at a hypothetical seeding rate of $30 \mathrm{seed} / \mathrm{m}^{2}$, and assuming $100 \%$ efficient germination and seed-to-seedling transmission, an incidence of $0.20 \%$ seed infestation represents the potential for one infected seedling per $16.7 \mathrm{~m}^{2}$, with potential for polycyclic propagation and dispersal of the pathogen for several months prior to development of the outbreak in spring 12 months later. Nonetheless, the finding that in-season fungicide applications were still necessary to manage the disease complex, despite planting heat-treated seed, should be treated with caution. The value of seed treatment appears to be in delaying colonization of pyrethrum foliage by the pathogens, with the effect being pathogen-specific and influenced by proximity to exogenous inoculum source(s). In the 2014 trial, in which entire fields were sown with heat-treated seed, there was a more limited response from winter fungicide treatments than reported previously (Hay et al. 2015). Whereas winter foliar fungicide application still had a significant effect on foliar disease in this study, the magnitude and duration of impact was less than reported by Hay et al. (2015), in which their experiments were conducted in pyrethrum fields planted with nontreated seed. Further investigation is warranted to identify whether the frequency of winter fungicide applications can be reduced if the proportion of pyrethrum fields planted with heat-treated seed in Australia increases.

This study has shown that the in-season, standard fungicide program used by pyrethrum growers in Australia is justified despite the planting of heat-treated seed for crop establishment. Nonetheless, it may be possible to further reduce the incidence of seedborne fungi by combining heat treatment with production of seed crops in a more arid region isolated from other pyrethrum crops. Pathogen avoidance, by growing in isolated regions and/or regions less favorable to the seed pathogen, is a strategy employed in many seed production systems to minimize seed contamination, such as in cucurbit seeds (Lovic and Hopkins 2003) and potato seed, in parts of North America (Radcliffe and Ragsdale 2002). Several isolated seed-crop locations were established in southern Tasmania, approximately $200 \mathrm{~km}$ from the nearest commercial pyrethrum field. Among the 12 seed lots assayed in 2014 (Fig. 1), two were produced in southern Tasmania and the remaining eight were produced in northern Tasmania within the commercial pyrethrum production region. Neither D. tanaceti nor $S$. tanaceti was recovered from the seed lots produced in southern Tasmania, whereas the pathogens were recovered from 22.6 and $16.9 \%$ of seeds, respectively, that were produced in northern Tasmania.

Although heat treatment of seed does not appear to obviate the need for foliar fungicide applications in pyrethrum, there are still reasons to improve seed health. Ray blight epidemics are strongly linked to seed contamination rates (Pethybridge et al. 2011) and the incidence of $S$. tanaceti was demonstrably reduced by the heat treatment of seed in this study. Thus, if used in conjunction with additional control measures to minimize crop infection by $D$. tanaceti from external sources, the benefits of heat treatment may become more evident. In the longer term, host resistance seems essential to reduce the need for in-season applications of fungicides for tan spot control because seed sanitation measures alone did not provide adequate suppression of the disease in this study.

\section{Acknowledgments}

We gratefully acknowledge the assistance of Mr. Craig Palmer and Mrs. Pattie Weichelt (TIA), Lynden Head (Botanical Resources Australia - Agricultural Services Pty. Ltd [BRA]), and staff of Botanical Resources Australia Pty. Ltd., for sample collection; and growers for allowing access to their fields. James McIver (formerly BRA) and Tim Groom (BRA) conducted most of the heat treatment of seed. Lindsey du Toit provided many comments and suggestions that improved this manuscript. We also acknowledge the financial supporters of our programs including BRA, the Pyrethrum Growers' Research and Development Committee, matching funds from the Australian Commonwealth Government through project PY12001 facilitated by Horticulture Innovation Australia Ltd., in-kind support of the Tasmanian Institute of Agriculture, and the United States Department of Agriculture - Agricultural Research Service CRIS 2072-21000-046-00.

\section{Literature Cited}

Barimani, M., Pethybridge, S. J., Vaghefi, N., Hay, F. S., and Taylor, P. W. J. 2013. A new anthracnose disease of pyrethrum caused by Colletotrichum tanaceti $\mathrm{sp}$ nov. Plant Pathol. 62:1248-1257.

Barnett, H. L. 1965. Illustrated Genera of Imperfect Fungi. Burgess Pub., Minneapolis, MN.

Chilvers, M. I., Jones, S., Meleca, J., Peever, T. L., Pethybridge, S. J., and Hay, F. S. 2014. Characterization of mating type genes supports the hypothesis that Stagonosporopsis chrysanthemi is homothallic and provides evidence that Stagonosporopsis tanaceti is heterothallic. Curr. Genet. 60:295-302.

Cleveland, W. S., Devlin, S. J., and Grosse, E. 1988. Regression by local fitting: methods, properties, and computational algorithms. J. Econom. 37:87-114.

Dobra, A., Dussi, M. C., Diaz, K., and Sugar, D. 2015. First report of Aureobasidium pullulans as a postharvest disease of 'Abate Fetel' pears from an organic orchard in Rio Negro, Argentina. Pages 579-582 in: Xii International Pear Symposium, vol. 1094. T. Deckers and J. Vercammen, eds. Int Soc Horticultural Science, Leuven, Belgium.

du Toit, L. J., and Hernandez-Perez, P. 2005. Efficacy of hot water and chlorine for eradication of Cladosporium variabile, Stemphylium botryosum, and Verticillium dahliae from spinach seed. Plant Dis. 89:1305-1312.

Eranthodi, A., Babadoost, M., and Trierweiler, B. 2010. Thermotherapy for control of fungal pathogens in propagative rootstocks of horseradish. HortScience 45: 599-604.

Grondeau, C., and Samson, R. 1994. A review of thermotherapy to free plant materials from pathogens, especially seeds from bacteria. Crit. Rev. Plant Sci. 13:57-75.

Hay, F. S., Gent, D. H., Pilkington, S., Pearce, T. L., Scott, J. B., and Pethybridge, S. J. 2015. Changes in distribution and frequency of fungi associated with a foliar disease complex of pyrethrum in Australia. Plant Dis. 99:1227-1235.

Hurvich, C. M., Simonoff, J. S., and Tsai, C. L. 1998. Smoothing parameter selection in nonparametric regression using an improved Akaike information criterion. J. Roy. Stat. Soc. B 60:271-293.

Jones, S. J., Hay, F. S., Harrington, T. C., and Pethybridge, S. J. 2011. First report of Boeremia blight caused by Boeremia exigua var. exigua on pyrethrum in Australia. Plant Dis. 95:1478-1479.

Kenward, M. G., and Roger, J. H. 1997. Small sample inference for fixed effects from restricted maximum likelihood. Biometrics 53:983-997.

Kim, Y. K. 2014. First report of a new postharvest rot in sweet cherries caused by Aureobasidium pullulans. Plant Dis. 98:424.

Lovic, B. R., and Hopkins, D. L. 2003. Production steps to reduce seed contamination by pathogens of cucurbits. HortTechnology 13:50-54.

Macdonald, W. L. 1995. Pyrethrum flowers - Production in Australia. Pages 55-66 in: Pyrethrum Flowers: Chemistry, Toxicology and Uses. Casida, J. E., and Quistad, G. B., eds. Oxford University Press, New York, NY.

Madden, L. V., Hughes, G., and van den Bosch, F. 2007. The Study of Plant Disease Epidemics. The American Phytopathological Society, St. Paul, MN.

McCormack, P., Wildman, H. G., and Jeffries, P. 1995. The influence of moisture on the suppression of Pseudomonas syringae by Aureobasidium pullulans on an artificial leaf surface. FEMS Microbiol. Ecol. 16:159-165.

Moslemi, A., Ades, P. K., Groom, T., Nicolas, M. E., and Taylor, P. W. J. 2017. Alternaria infectoria and Stemphylium herbarum, two new pathogens of pyrethrum (Tanacetum cinerariifolium) in Australia. Austral. Plant Pathol. 46:91-101.

Parsa, S., Garcia-Lemos, A. M., Castillo, K., Ortiz, V., Lopez-Lavalle, L. A. B. Braun, J., and Vega, F. E. 2016. Fungal endophytes in germinated seeds of the common bean, Phaseolus vulgaris. Fungal Biol. 120:783-790.

Pearce, T. L., Scott, J. B., Crous, P. W., Pethybridge, S. J., and Hay, F. S. 2016a Tan spot of pyrethrum is caused by a Didymella species complex. Plant Pathol. 65:1170-1184. 
Pearce, T. L., Scott, J. B., Hay, F. S., and Pethybridge, S. J. 2016b. Mating-type gene structure in Didymella tanaceti and their spatial distribution in pyrethrum fields. Phytopathology 106:1521-1529.

Pethybridge, S. J., Gent, D. H., Groom, T., and Hay, F. 2013. Minimizing crop damage through understanding relationships between pyrethrum phenology and ray blight disease severity. Plant Dis. 97:1431-1437.

Pethybridge, S. J., Gent, D. H., and Hay, F. S. 2011. Epidemics of ray blight on pyrethrum are linked to seed contamination and overwintering inoculum of Phoma ligulicola var. inoxydabilis. Phytopathology 101:1112-1121.

Pethybridge, S. J., Hay, F., Jones, S., Wilson, C., and Groom, T. 2006. Seedborne infection of pyrethrum by Phoma ligulicola. Plant Dis. 90:891-897.

Pethybridge, S. J., Hay, F. S., Esker, P. D., Gent, D. H., Wilson, C. R., Groom, T., and Nutter, F. W. 2008a. Diseases of pyrethrum in Tasmania: challenges and prospects for management. Plant Dis. 92:1260-1272.

Pethybridge, S. J., Hay, F. S., Groom, T., and Wilson, C. R. 2008b. Improving fungicide-based management of ray blight disease in Tasmanian pyrethrum fields. Plant Dis. 92:887-895.

Pethybridge, S. J., Hay, F. S., and Wilson, C. R. 2004. Pathogenicity of fungi commonly isolated from foliar disease in Tasmanian pyrethrum crops. Austral. Plant Pathol. 33:441-444.

Pethybridge, S. J., Hay, F. S., Wilson, C. R., and Groom, T. 2005. Development of a fungicide-based management strategy for foliar disease caused by Phoma ligulicola in Tasmanian pyrethrum fields. Plant Dis. 89:1114-1120.

Pethybridge, S. J., Jones, S. J., Shivas, R. G., Hay, F. S., Wilson, C. R., and Groom, T. 2008c. Tan spot: a new disease of pyrethrum caused by Microsphaeropsis tanaceti sp. nov. Plant Pathol. 57:1058-1065.
Pethybridge, S. J., and Wilson, C. R. 1998. Confirmation of ray blight disease of pyrethrum in Australia. Austral. Plant Pathol. 27:45-48.

R Core Team. 2015. R: A Language and Environment for Statistical Computing. R Foundation for Statistical Computing, Vienna, Austria.

Radcliffe, E. B., and Ragsdale, D. W. 2002. Aphid-transmitted potato viruses: The importance of understanding vector biology. Am. J. Potato Res. 79:353-386.

Rist, D. L., and Rosenberger, D. A. 1995. A storage decay of apple fruit caused by Aureobasidium pullulans. Plant Dis. 79:425.

Scott, J. B., Gent, D. H., Hay, F. S., and Pethybridge, S. J. 2015. Estimation of pyrethrum flower number using digital imagery. HortTechnology 25:617-624.

Scott, J. B., Gent, D. H., Pethybridge, S. J., Groom, T., and Hay, F. S. 2014. Crop damage from Sclerotinia crown rot and risk factors in pyrethrum. Plant Dis. 98:103-111.

Shah, D. A., and Madden, L. V. 2004. Nonparametric analysis of ordinal data in designed factorial experiments. Phytopathology 94:33-43.

Vaghefi, N., Ades, P. K., Hay, F. S., Pethybridge, S. J., Ford, R., and Taylor, P. W. J. 2015. Identification of the MAT1 locus in Stagonosporopsis tanaceti, and exploring its potential for sexual reproduction in Australian pyrethrum fields. Fungal Biol. 119:408-419.

Vaghefi, N., Pethybridge, S. J., Ford, R., Nicolas, M. E., Crous, P. W., and Taylor, P. W. J. 2012. Stagonosporopsis spp. associated with ray blight disease of Asteraceae. Austral. Plant Pathol. 41:675-686.

Webb, T. A., and Mundt, J. O. 1978. Molds on vegetables at time of harvest. Appl. Environ. Microbiol. 35:655-658.

Zito, S. W., Zieg, R. G., and Staba, E. J. 1983. Distribution of pyrethrins in oil glands and leaf tissue of Chrysanthemum cinerariaefolium. Planta Med. 47: 205-207. 